\title{
Allosteric Modulation of NMDARs Reverses Patients' Autoantibody Effects in Mice
}

\author{
Marija Radosevic, PhD, * Jesús Planagumà, PhD, * Francesco Mannara, PhD, * Araceli Mellado, BS, \\ Esther Aguilar, BS, Lidia Sabater, PhD, Jon Landa, MSc, Anna García-Serra, PhD, Estibaliz Maudes, MSc, \\ Xavier Gasull, PhD, Mike Lewis, PhD, † and Josep Dalmau, MD, PhD†
}

Neurol Neuroimmunol Neuroinflamm 2022;9:e1122. doi:10.1212/NXI.0000000000001122

\author{
Correspondence \\ Dr. Dalmau \\ jdalmau@clinic.cat
}

\begin{abstract}
\section{Background and Objectives}

To demonstrate that an analog (SGE-301) of a brain-derived cholesterol metabolite, 24(S)hydroxycholesterol, which is a selective positive allosteric modulator (PAM) of NMDA receptors (NMDARs), is able to reverse the memory and synaptic alterations caused by CSF from patients with anti-NMDAR encephalitis in an animal model of passive transfer of antibodies.
\end{abstract}

\section{Methods}

Four groups of mice received (days 1-14) patients' or controls' CSF via osmotic pumps connected to the cerebroventricular system and from day 11 were treated with daily subcutaneous injections of SGE-301 or vehicle (no drug). Visuospatial memory, locomotor activity (LA), synaptic NMDAR cluster density, hippocampal long-term potentiation (LTP), and paired-pulse facilitation (PPF) were assessed on days 10, 13, 18, and 26 using reported techniques.

\section{Results}

On day 10, mice infused with patients' CSF, but not controls' CSF, presented a significant visuospatial memory deficit, reduction of NMDAR clusters, and impairment of LTP, whereas LA and PPF were unaffected. These alterations persisted until day 18, the time of maximal deficits in this model. In contrast, mice that received patients' CSF but from day 11 were treated with SGE-301 showed memory recovery (day 13), and on day 18, all paradigms (memory, NMDAR clusters, and LTP) had reversed to values similar to those of controls. On day 26, no differences were observed among experimental groups.

\section{Discussion}

An oxysterol biology-based PAM of NMDARs is able to reverse the synaptic and memory deficits caused by CSF from patients with anti-NMDAR encephalitis. These findings suggest a novel adjuvant treatment approach that deserves future clinical evaluation.

\footnotetext{
*These authors contributed equally as co-first authors.

†These authors contributed equally as co-senior authors.

From the Institut d'Investigacions Biomèdiques August Pi i Sunyer (IDIBAPS) (M.R., J.P., F.M., A.M., E.A., L.S., J.L., A.G.-S., E.M., X.G., J.D.), Hospital Clínic, Universitat de Barcelona, Barcelona, Spain; Laboratori de Neurofisiologia (X.G.), Departament de Biomedicina, Facultat de Medicina i Ciències de la Salut, Institut de Neurociències, Universitat de Barcelona, Barcelona, Spain; Sage Therapeutics (M.L.), Department of Research and Nonclinical Development, Cambridge, MA; Department of Neurology (I.D.), University of Pennsylvania, Philadelphia, PA; Centro de Investigación Biomédica en Red de Enfermedades Raras (CIBERER) (J.D.), Madrid, Spain; and Institució Catalana de Recerca i Estudis Avançats (ICREA) (J.D.), Barcelona, Spain.
}

Go to Neurology.org/NN for full disclosures. Funding information is provided at the end of the article.

The Article Processing Charge was funded by the authors.

This is an open access article distributed under the terms of the Creative Commons Attribution-NonCommercial-NoDerivatives License 4.0 (CC BY-NC-ND), which permits downloading and sharing the work provided it is properly cited. The work cannot be changed in any way or used commercially without permission from the journal. 


\section{Glossary}

EPSC $=$ excitatory postsynaptic current $;$ HPBCD $=2$-hydroxypropyl $-\beta$-cyclodextrin $;$ LA = locomotor activity; $\mathbf{L T P}=$ long-term potentiation; NMDAR = NMDA receptor; NOL = novel object location; PAM = positive allosteric modulator; PPF = pairedpulse facilitation.

Anti-NMDA receptor (NMDAR) encephalitis is an immunemediated disease characterized by a complex neuropsychiatric syndrome and the presence of CSF antibodies against the GluN1 subunit of NMDAR ${ }^{1}$ Although most patients improve with immunotherapy and tumor removal, when needed, one of the most challenging problems of this disease is the prolonged process of recovery. ${ }^{2-7}$ This problem particularly affects memory, attention, and executive functions that usually remain altered for many months after the acute phase has resolved. ${ }^{8-13}$ The reasons for this slow recovery are unclear, but it may be caused by a severe impairment of synaptic function due to persistent immune activation against NMDAR within the CNS, ${ }^{14,15}$ a limited efficacy of current immunotherapies, or a combination thereof.

To achieve a faster or sustained improvement, we postulated that patients with anti-NMDAR encephalitis may need, in addition to immunotherapy, adjuvant medication aimed to compensate or overcome the mechanisms altered by the antibodies. This approach would be similar to that used in patients with myasthenia gravis or the Lambert-Eaton myasthenic syndrome who receive immunotherapy along with acetylcholinesterase inhibitors or 3,4diaminopyridine. ${ }^{16,17}$ Considering that in anti-NMDAR encephalitis, the antibodies cause a reduction of receptors and NMDARmediated currents, ${ }^{14,18}$ the potential treatment utility of positive allosteric modulators (PAMs) of NMDARs came to our attention.

There is evidence that a brain-derived cholesterol metabolite, 24(S)-hydroxycholesterol (24(S)-HC), is a potent, direct, and selective PAM of NMDARs. ${ }^{19}$ Several synthetic analogs of 24(S)$\mathrm{HC}$ such as $\Delta 5,6-3 \beta$-oxy-nor-cholenyl-dimethylcarbinol (SGE201) and SGE-301 have similar mechanisms of action. ${ }^{19}$ An advantage of these compounds is their small size and lipophilicity that allow them to cross the blood-brain barrier and reach CNS concentrations that substantially potentiate NMDAR currents. ${ }^{19-21}$ In rats, administration of SGE-301 reversed the memory deficit caused by phencyclidine, a noncompetitive NMDAR antagonist, ${ }^{19}$ and in mice, it prevented the development of memory and synaptic alterations caused by cerebroventricular transfer of patients' NMDAR antibodies. ${ }^{20}$ However, the potential treatment efficacy of SGE-301 in reversing the antibody-mediated effects once the memory and synaptic alterations have already occurred was not investigated. Here, we address this question in the model of cerebroventricular transfer of patients' CSF antibodies.

\section{Methods}

\section{Animals, Surgery, and Patients' CSF}

One hundred forty-one male C57BL/6J mice (Charles River), 8-10 weeks old, were used in the studies, including 44 for assessment of memory and locomotor activity (LA), 50 for determination of clusters of NMDAR and PSD95 using confocal immunohistochemistry, and 47 for assessment of hippocampal long-term potentiation (LTP) and paired-pulse facilitation. Animal care, anesthesia, and the technique of cerebroventricular infusion of patients' CSF via subcutaneous osmotic pumps (Alzet; volume 100 microliter, flow rate 0.25 microliter/h for 14 days) have been described. ${ }^{18}$ The CSF infused was pooled from samples of 10 patients with high titer IgG GluN1 antibodies (all $>1: 320$ ) and 10 patients with normal pressure hydrocephalus without antibodies (control); samples were dialyzed against phosphate-buffered saline and normalized to a physiologic concentration of $2 \mathrm{mg} \mathrm{IgG/dL}{ }^{22}$ The same samples were previously used in a report where the NMDAR antibody specificity and absence of other neuronal antibodies were demonstrated by immunoabsorption with HEK293 cells expressing GluN1, and abrogation of CSF-mediated NMDAR internalization after CSF was immunoabsorbed with GluN1. ${ }^{20}$

\section{Standard Protocol Approvals, Registrations, and Patient Consents}

Written informed consent was obtained from patients, and the study was approved by the local institutional review board (Hospital Clínic, HCB/2018/0192). The Local Ethical Committee of the University of Barcelona following European (2010/63/UE) and Spanish (RD 53/2013) regulations approved the animal studies.

\section{Preparation of SGE-301 and Experimental Design}

Lyophilized SGE-301 was dissolved in a solution of $30 \%$ 2-hydroxypropyl- $\beta$-cyclodextrin (HPBCD, Sigma-Aldrich), and the dose $(10 \mathrm{mg} / \mathrm{kg})$ for subcutaneous administration was based on previously reported plasma and brain pharmacokinetic studies that demonstrated brain exposures sufficient to modulate activity in preclinical models of NMDAR hypofunction. ${ }^{19,20}$ A similar solution of $30 \%$ HPBCD, without drug, served as control (vehicle).

From days 1 to 14, mice were continuously infused in the cerebroventricular system with patients' or controls' CSF. From days 11 to 19 , each experimental condition was divided into 2 additional groups depending on whether animals were treated with SGE-301 or vehicle (control) (Figure 1A). The treatment interval (days 11-19) was selected according to previous experience with this model, which consistently shows progressive impairment of memory along with a decrease of NMDAR clusters from days 10 to $18 .^{18,20,22}$ Brain tissue studies were performed in subsets of mice killed at intermediate time points (days 10 and 18) and in the rest of animals killed on day 26 (Figure 1B). 


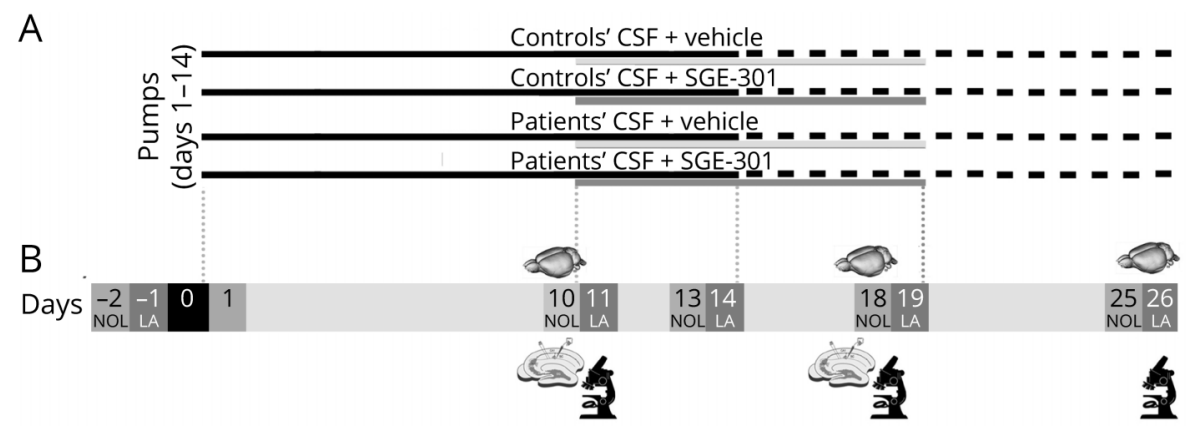

(A) Studies were performed in 4 experimental groups of mice that received a continuous infusion (days 1-14) of controls' or patients' CSF via subcutaneously implanted osmotic pumps connected to the cerebroventricular system along with daily subcutaneous injection of vehicle (no drug) or SGE-301 (10 $\mathrm{mg} / \mathrm{kg}$ diluted in vehicle) from days 11 to 19 . Note that before starting treatment on day 11 , there are 2 experimental groups (mice infused with controls' CSF or patients' CSF). (B) Timing of memory and locomotor tasks. Baseline novel object location (NOL) and locomotor activity (LA) were obtained before the infusion of controls' or patients' CSF (days $-2,-1)$. The same tests were applied on days $10-11,13-14,18-19$, and 25-26 after onset of infusion of CSF. The effects of patients' antibodies on the levels of NMDARs or LTP were examined in subsets of mice killed on days $10-11,18-19$, or 26 . LTP = long-term potentiation; NMDAR = NMDA receptor.

\section{Immunohistochemistry, Immunoprecipitation, Confocal Microscopy, and Electrophysiological Studies}

The presence of human IgG bound to brain tissue was quantified using immunofluorescence, as reported. ${ }^{23}$ The NMDAR specificity of the IgG bound to brain was demonstrated by immunoprecipitation. In brief, homogenates of brain tissue were washed, incubated with protein $\mathrm{A} / \mathrm{G}$ sepharose beads, precipitated, run in a gel, and blotted with an polyclonal rabbit GluN1 antibody (G8913, 1:200, SigmaAldrich, St. Louis, MO), as reported. ${ }^{22}$

To determine the effects of patients' antibodies on the number of clusters of NMDAR, nonpermeabilized 5 - $\mu$ m-thick brain sections (obtained on days 10,18, and 26) were immunohistochemically studied as reported. ${ }^{18}$ In brief, sections were serially incubated with a human CSF NMDAR antibody (1:20, used as primary antibody), and the labeled NMDARs were determined with a secondary Alexa Fluor 488 goat anti-human IgG (1:1000, A-11013, Thermo Fisher, Waltham, MA). Sections were then permeabilized and incubated with a polyclonal rabbit anti-PSD95 (1:250, ab18258 Abcam, Cambridge, UK) followed by a secondary Alexa Fluor 594 goat anti-rabbit IgG (1:1000, A-11012, ThermoFisher). Slides were mounted and results scanned with the Zeiss LSM710 confocal microscope (Carl Zeiss, Jena, Germany) with the EC-Plan NEOFLUAR CS $100 \times / 1.3$ NA oil objective. For each animal, 5 identical image z-stacks (each stack comprising 50 optical images) from 3 hippocampal areas, CA1, CA3, and dentate gyrus (total 15 image z-stacks), were acquired. ${ }^{18}$ The mean density of clusters of NMDAR or PSD95 was obtained using a spot detection algorithm from Imaris suite v.8.1 (Oxford Instruments, Belfast, UK). The clusters of NMDAR that colocalized with PSD95 were defined as synaptic. Acute hippocampal sections in subsets of mice killed on days 10 or 11, and 18-20 after CSF infusion onset were used for electrophysiologic assessment of LTP and PPF, as reported. ${ }^{22}$

\section{Memory and Locomotor Activity Tasks}

Visuospatial memory was determined by the discrimination index obtained from the novel object location (NOL) test, before the infusion of CSF (baseline) and on days 10,13, 18, and 25 after infusion onset. LA was automatically determined using LA boxes $(11 \times 21 \times 18 \mathrm{~cm}$, Imetronic, Pessac, France $)$ for 1 hour, at baseline, and on days $11,14,19$, and 26, as reported $^{18}$ (Figure 1B).

\section{Statistical Analysis}

Data from experiments measuring cluster densities of NMDAR and PSD95 in the brain were assessed using the Kruskal-Wallis test comparing ranks, as populations were not normally distributed according to the D'Agostino-Pearson test and Dunn corrections for multiple comparisons. The analysis of human IgG deposits and electrophysiologic data were assessed by 1-way ANOVA and unpaired $t$ tests. NOL index and LA data were analyzed using repeated-measures 2-way ANOVA. All ANOVA tests included post hoc analyses with Bonferroni correction for multiple testing. In all statistical analyses, $p$ value $<0.05$ was considered significant. For all experiments, the distribution of the data was assessed for outliers and normality. Statistical analyses were performed with GraphPad Prism v.8 (La Jolla, CA).

\section{Data Availability}

Data supporting these findings are available on reasonable request.

\section{Results}

\section{Presence of NMDAR-Specific IgG in the Brains of Mice Infused With Patients' CSF}

Compared with mice infused with controls' CSF, those infused with patients' CSF had a higher content of human IgG in the brain regardless of whether animals had been treated with SGE-301 or vehicle (Figure 2A). Immunoprecipitation 


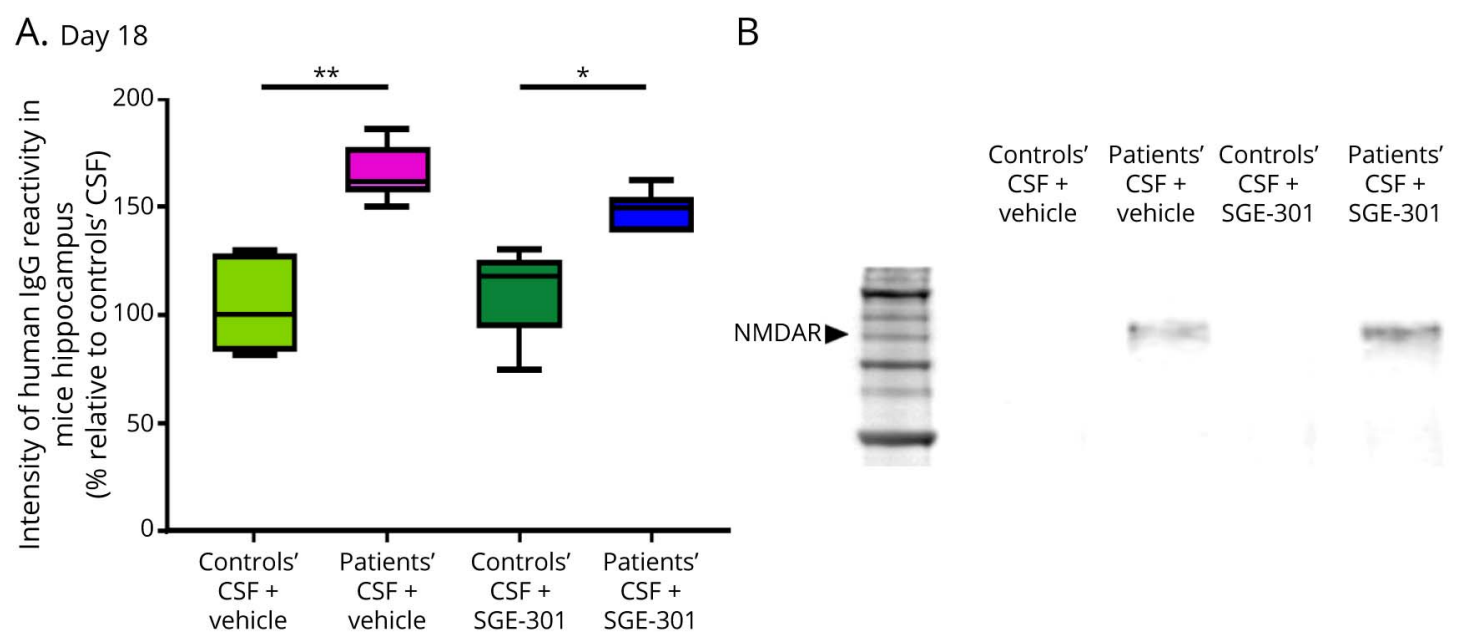

(A) Quantification of human IgG immunofluorescence intensity in the brain of mice infused with patients' or controls' IgG shows an increased amount of human IgG in mice infused with patients' CSF regardless of whether mice received treatment with SGE-301 or vehicle. The median intensity of IgG immunofluorescence in the brain of mice infused with controls' CSF was defined as 100\%. The number of mice per experimental group is 5 . Data presented in box plots show the median and 25th, and 75th percentiles; whiskers indicate minimum and maximum. The significance of treatment effect was assessed by 1 -way ANOVA. ${ }^{*} p=0.0318 ;{ }^{\star \star} p=0.0064$. (B) Immunoprecipitation of NMDAR-bound IgG from mice brain exposed to patients' CSF or controls' CSF with or without SGE-301. The predicted molecular weight of $105 \mathrm{kDa}$ (arrowhead) corresponds to the GluN1 subunit of the NMDAR. Each lane corresponds to the immunoprecipitation of 1 brain per each indicated condition. NMDAR = NMDA receptor.

studies showed that the IgG was specifically bound to NMDAR (Figure 2B). These findings are confirmatory of a previous study indicating that SGE-301 does not block the binding of patients' antibodies to NMDARs. ${ }^{20}$

\section{Treatment With SGE-301 Reversed the Structural and Functional Synaptic Effects of Patients' CSF}

The effect of patients' or controls' CSF on the density of total cell surface or synaptic NMDAR clusters in hippocampus was examined in 50 mice, including 5 animals for each experimental group at 3 time points (days 10,18, and 26). For each animal, 15 hippocampal areas were investigated (Figure $3 \mathrm{~A}$ ). A representative $\mathrm{CA} 1$ area of each experimental condition (e.g., 1 of the squares in $\mathrm{A}$, right panel) on day 18 is shown at higher magnification in panel 3B. On days 10 and 18, animals infused with patients' CSF and treated with subcutaneous vehicle (without SGE-301) showed a significant decrease of total cell surface and synaptic NMDARs compared with animals infused with controls' CSF (Figure 3, C and D). In contrast, animals infused with the same patients' CSF but treated from day 11 with SGE-301 showed no changes in total or synaptic levels of NMDARs on day 18 (Figure 3D). On day 26 (12 days after the infusion of patients' CSF antibodies had stopped), the levels of total and synaptic NMDAR in all experimental groups had returned to the value of controls, as expected in this model (Figure 3E). No effects on the levels of PSD95 were observed in any of the time points investigated (days 10,18, and 26) for all experimental groups (Figure 3B, red channel, and eFigure 1, links. lww.com/NXI/A672).

Hippocampal electrophysiologic studies were performed in a total of 69 hippocampal slices from 47 mice representing the 4 experimental groups (Figure 4A). On day 10 (before treatment with SGE-301 started), these studies showed that animals infused with patients' CSF had severe impairment of LTP compared with animals infused with controls' CSF (Figure 4, B, D, F). This impairment of hippocampal plasticity persisted until day 18 except for the group of animals that were treated with SGE-301. Indeed, animals that received the same patients' CSF and were treated from day 11 with SGE-301 had normalized LTP and memory function on day 18 (Figure 4, C, E, G).

In contrast to the severe impairment of LTP caused by patients' CSF in untreated animals, the field excitatory postsynaptic potential recordings following a standard paired-pulse protocol showed in all experimental groups ( 2 on day 10 and 4 on day 18) a significant facilitation consistent with increased presynaptic release probability (Figure 5). This finding indicates that the effects of patients' CSF antibodies are predominantly postsynaptic, as reported, ${ }^{20,22}$ and that SGE-301 did not significantly modify presynaptic release probability.

\section{Treatment With SGE-301 Reversed the Memory Loss Caused by Patients' CSF}

A total of 44 mice (10-12 per experimental group) were included in these studies. Compared with controls, animals infused with patients' CSF showed visuospatial memory deficits at first evaluation on day 10 (Figure 6). This memory deficit persisted until day 18 (which in this model is the time of maximal effects) and progressively recovered after the infusion of patients' CSF had stopped. In contrast, animals infused with the same patients' CSF but that from day 11 received treatment with subcutaneous SGE-301 showed a rapid recovery of memory, which as of day 13 became similar to that 
A
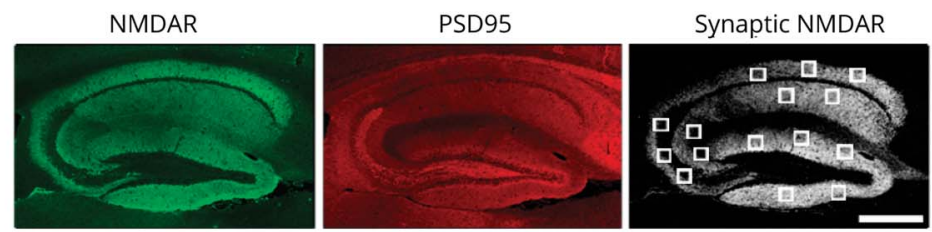

B
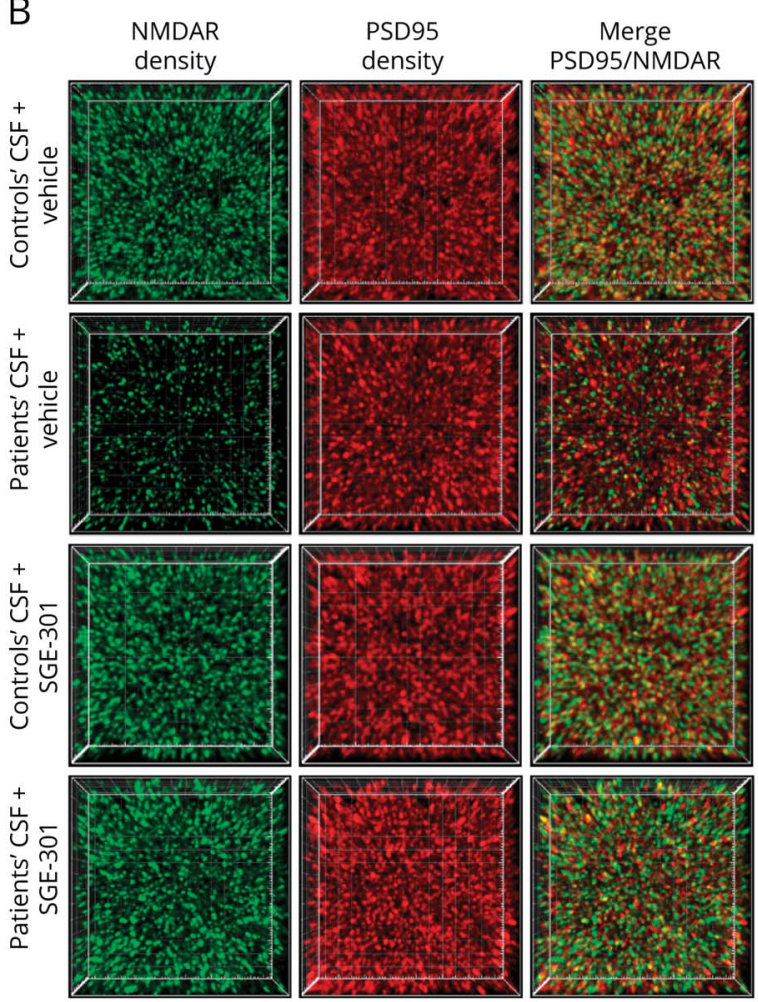

Synaptic NMDAR density
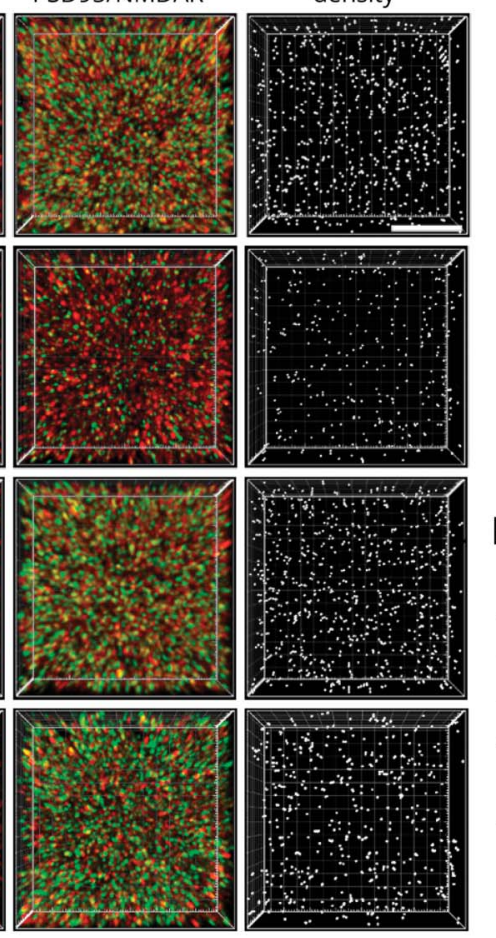

C. Day 10

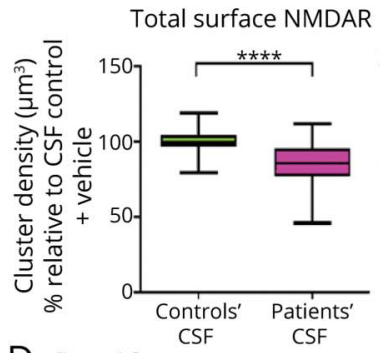

Synaptic NMDAR

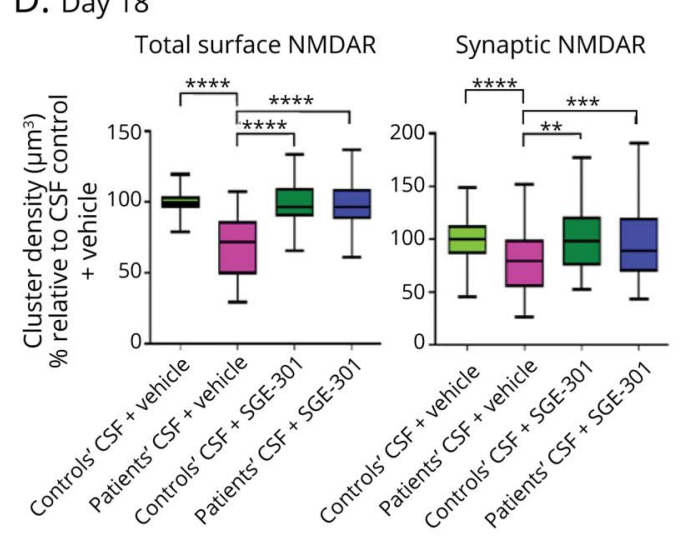

E. Day 26

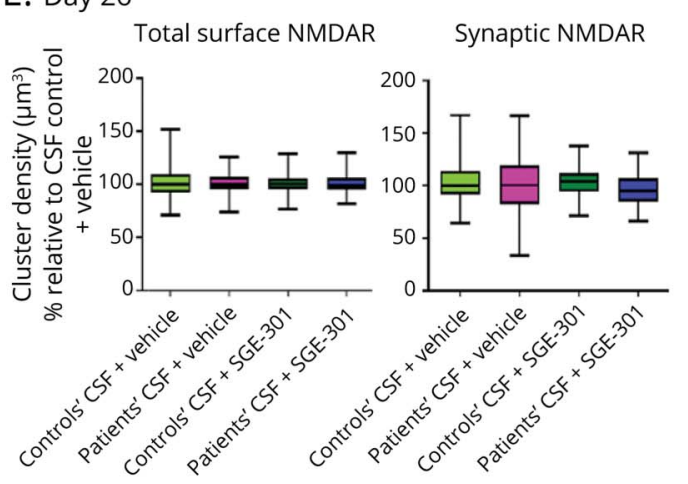

(A) Hippocampus of the mouse immunolabeled for NMDAR (green) and PSD95 (red). Images were merged to demonstrate colocalizing clusters (defined as synaptic NMDAR, white color). The 15 small white squares indicate the analyzed areas in CA1, CA3, and dentate gyrus (5 each). Each square is a 3D stack of 50 sections. Scale bar $=400 \mu \mathrm{m}$. (B) Four magnified squares (3D projection) of a CA1 region of hippocampus representing the 4 experimental conditions and showing the analysis of density of total cell surface NMDAR, PSD95, and synaptic NMDAR clusters on day 18. The images (NMDAR, green; PSD95, red) were postprocessed and used to calculate the density of the clusters (density $=s p o t s / \mu \mathrm{m}^{3}$ ). Scale bar $=5 \mu \mathrm{m}$. Quantification of the density of total surface NMDAR and synaptic NMDAR clusters on day 10 (C), day 18 (D), and day 26 (E) in a pooled analysis of the 15 hippocampal areas (CA1, CA3, and dentate gyrus) for each experimental condition. Mean density of clusters in animals treated with controls' CSF + vehicle was defined as $100 \%$. For each condition, 5 animals were examined. Box plots show the median and 25 th and 75 th percentiles; whiskers indicate the minimum and maximum values. Significance of the treatment effect was assessed using the Kruskal-Wallis test, $* \star \star \star x p<0.0001 ; * \star \star x p 0.001 ; * \star p=0.008$. NMDAR $=$ NMDA receptor.

of controls. These animals not only showed earlier memory recovery but also remained without memory deficits even though from day 11 to 14 they continued receiving patients' CSF antibodies. The total time of exploration of the 2 objects (not moved + novel location) was similar in animals of the 4 experimental groups (data not shown). No abnormal behavior or side effects were observed in animals infused with controls' CSF and treated with SGE-301. The LA was also similar in the 4 groups (data not shown).

Taken together, treatment with SGE-301 resulted in an improvement of memory deficits and restoration of synaptic levels of NMDAR and LTP that had been impaired by CSF from patients with anti-NMDAR encephalitis. The treatment effect was particularly notable on day 18 , when all paradigms (memory, clusters of NMDAR, and LTP) are consistently impaired in this model but, as shown here, were reversed to normal after treatment with SGE-301.

\section{Discussion}

We show that SGE-301, a synthetic analog of a major brainderived cholesterol metabolite, 24(S)-HC, reversed the pathogenic effects of CSF from patients with anti-NMDAR 

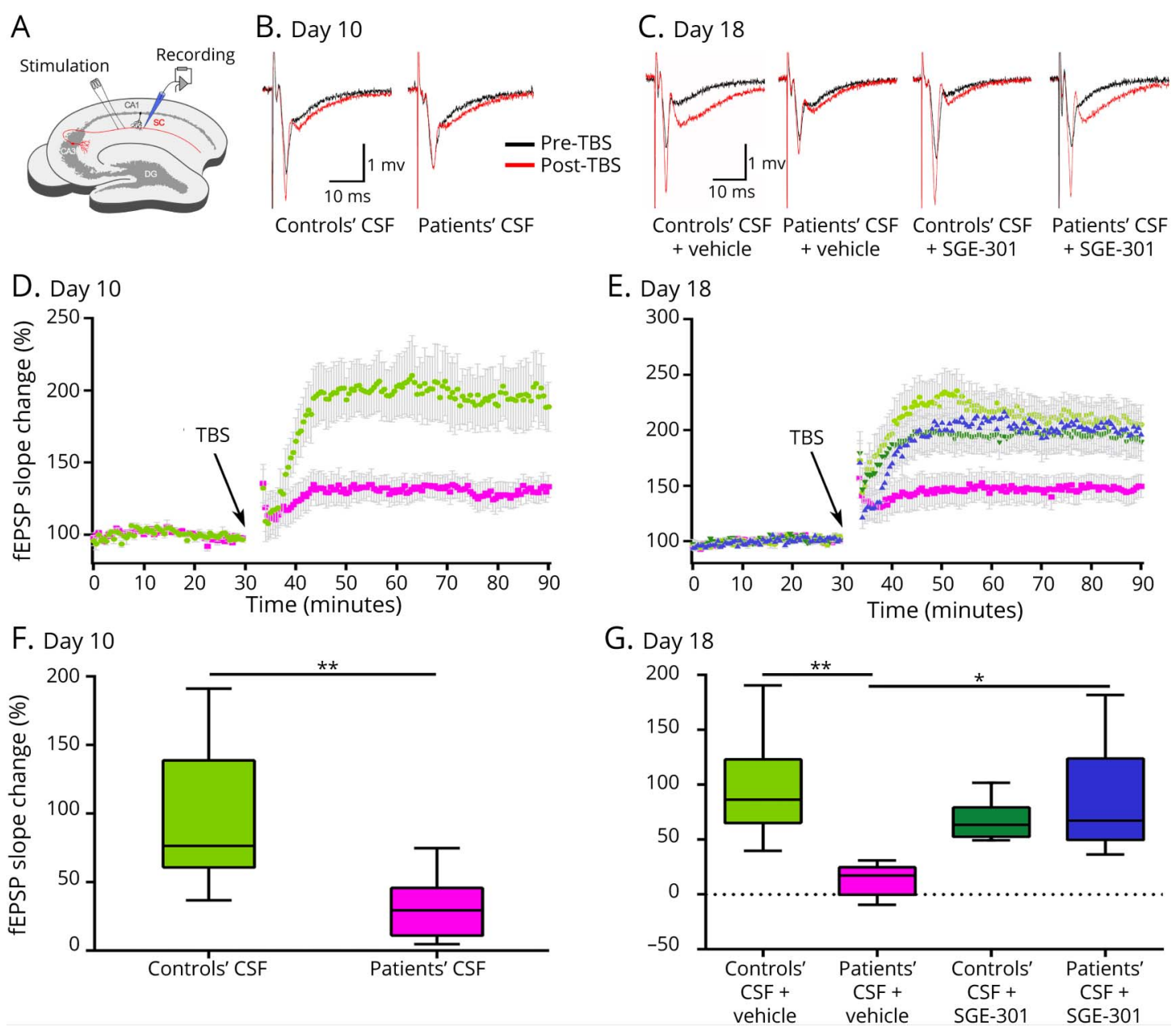

(A) The Schaffer collateral pathway (SC, red) was stimulated, and field potentials were recorded in the CA1 region of the hippocampus. Long-term potentiation (LTP) was induced by theta-burst stimulation (TBS); $D G$ = dentate gyrus; CA = cornu ammonis. (B and C) Example traces of individual recordings showing baseline field excitatory postsynaptic potentials (fEPSPs) before LTP induction (black traces) and after LTP (red traces) (B) at day 10 and (C) day 18. (D and E) Time course of fEPSP recordings at day 10 (D) and day 18 (E) showing robust changes in the fEPSP slope in the animals infused with controls' CSF treated or not with SGE-301 (dark or light green traces) and in the animals infused with patients' CSF treated with SGE-301 (day 18, blue trace). Animals infused with the same patients' CSF but not treated with SGE-301 showed a marked impairment of LTP induction (pink traces in D and E). The fEPSP slopes of all animals for each of the groups are presented as mean \pm SEM. (F and G) Quantification of the fEPSP slope change showing a significant reduction of the fEPSP slope in animals infused with patients' CSF not treated with SGE-301 compared with animals infused with the same patients' CSF treated with SGE-301 or animals infused with controls' CSF (treated or untreated with SGE-301). Number of slices and animals used on day 10: controls' CSF, number of acute slices $n=7$ from 6 mice; patients' CSF, $n=8$ from 6 mice. Day 18: controls' CSF + vehicle, $n=8$ from 6 mice; patients' CSF + vehicle, $n=9$ from 7 mice; controls' CSF + SGE-301, $n=8$ from 6 mice; and patients' CSF + SGE-301, $\mathrm{n}=8$ from 6 mice. Box plots show the median and 25th and 75th percentiles; whiskers indicate minimum and maximum values. Significance was assessed using 1-way ANOVA, and the Bonferroni post hoc correction test was applied. Day 10: ${ }^{\star \star} p=0.0063$ and day $18: \star \star p=0.0039$, $\star_{p}=0.0229$

encephalitis, including the antibody-mediated reduction of NMDAR clusters and impairment of visuospatial memory and synaptic plasticity. These findings are important considering that the main treatment options currently available for antiNMDAR encephalitis are limited to escalation of immunotherapy and symptom management (e.g., psychosis, seizures, autonomic dysregulation, or hypoventilation) with nondisease-specific treatments. ${ }^{24}$ Although this treatment approach is successful in improving or resolving the symptoms of the acute phase of the disease in $75 \%-80 \%$ of patients, virtually all patients transition to a second stage characterized by prolonged deficits of memory, attention, and executive functions. These deficits usually show a slow progressive improvement over many months, or in some patients, they remain as persistent sequelae. ${ }^{2,3,7,13,25,26}$ The mechanisms underlying this protracted stage of the disease are less known than those of the acute stage; for example, the signs of inflammation (CSF pleocytosis and MRI changes) usually observed in the initial stage are no longer present despite that NMDAR antibodies are detectable in $\mathrm{CSF}^{27}$ The usefulness of immunotherapy during this second stage is also unclear, and there are no guidelines for treatment. Some investigators maintain treatment with first- or second-line immunotherapies for 1-2 years or use mycophenolate mofetil or azathioprine, ${ }^{28}$ whereas others (including ourselves) use symptomatic treatment and a close follow-up to promptly retreat with immunotherapy if there is clinical worsening. 
A. Day 10

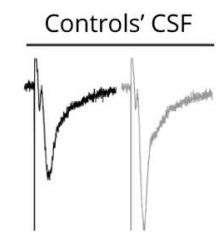

C. Day 10
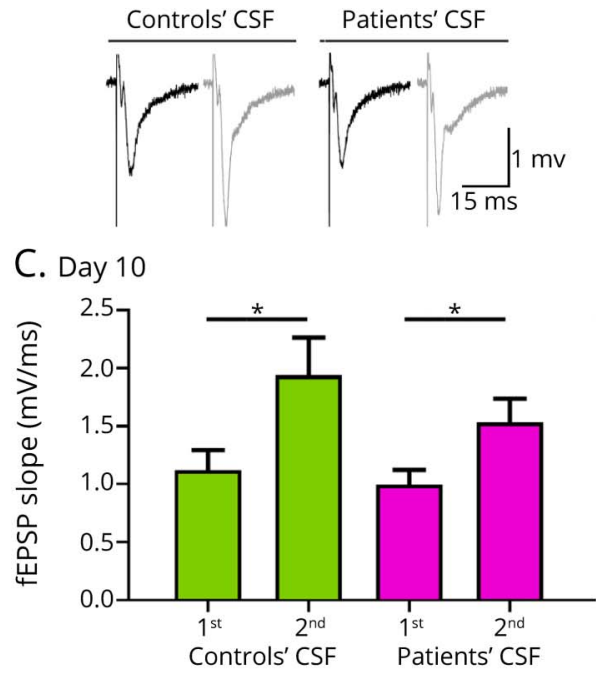

B. Day 18

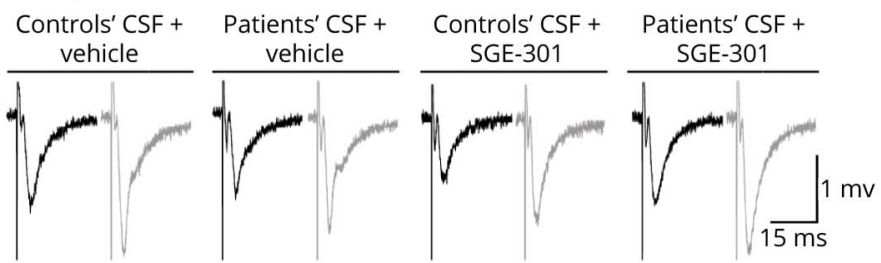

D. Day 18

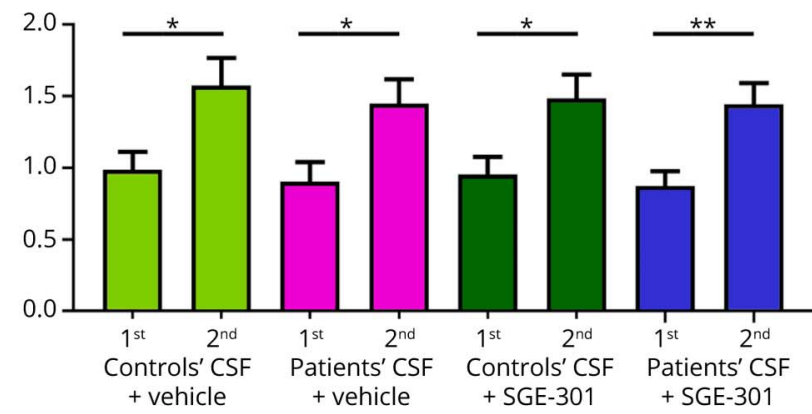

E. Day 10

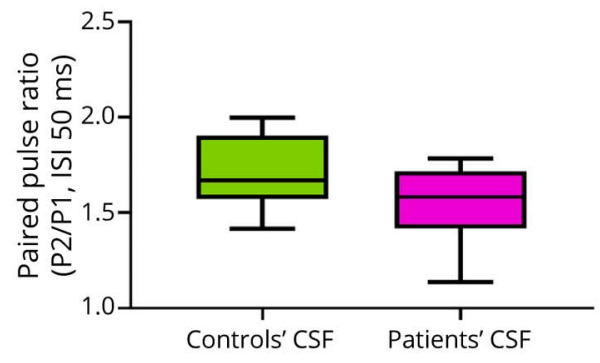

F. Day 18

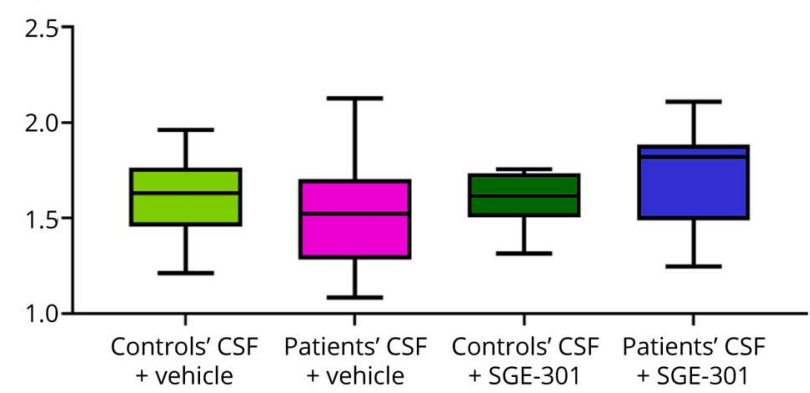

(A and B) Example traces of fEPSPs in the paired-pulse facilitation protocol applied to the Schaffer collateral-CA1 synaptic region on days 10 (A) and 18 (B). In all experimental groups, the fEPSP slope and amplitude in the response to the second stimulus (gray) are increased compared with the fEPSP slope and amplitude after the first stimulus (black). The interstimulus interval is $50 \mathrm{~ms}$. (C and D) Mean slope values of fEPSP responses obtained after the first (1st) stimulus and second (2nd) stimulus on days 10 (C) and 18 (D). All experimental groups of animals show a significant increase in the fEPSP slope after the second stimulus. Number of slices and animals used on day 10: controls' CSF ( $n=8$ recordings from 5 animals); patients' CSF ( $n=10$ recordings from 7 animals). Day 18: controls' CSF + vehicle ( $n=14$ recordings from 9 animals, light green); patients' CSF + vehicle ( $n=14$ recordings from 9 animals, pink); controls' CSF + SGE-301 ( $n=10$ recordings from 8 animals, dark green); patients' CSF + SGE-301 ( $n=13$ recordings from 9 animals, blue). Data are shown as mean \pm SEM. Significance of the fEPSP slope increase on the second stimulus was assessed by unpaired $t$ tests. Day 10 : controls' CSF, ${ }^{*} p=0.0424 ;$ patients' CSF ${ }^{*} p=0.0380$. Day 18: controls' CSF + vehicle, ${ }^{*} p=0.0162 ;$ patients' CSF + vehicle, ${ }^{\star} p=0.0424$; controls' CSF + SGE-301, ${ }^{\star} p=0.0194 ;$ patients' CSF + SGE-301, ** $p<0.0039$. (E and F) Paired-pulse facilitation, calculated as P2/P1 (pulse 2/pulse 1) fEPSP slope ratio, is not altered in any of the experimental groups of animals on days 10 (E) and 18 (F) when compared with that of the group infused with controls' CSF + vehicle. The number of recordings and animals used are the same as those indicated above. Box plots show the median and 25th and 75th percentiles; whiskers indicate minimum and maximum values. The significance of the results was assessed using 1-way ANOVA. fEPSP = field excitatory postsynaptic potential.

The model of cerebroventricular transfer of patients' CSF that we have used here shows more similarities to the second stage than to the initial stage of anti-NMDAR encephalitis. In this model, animals receive patients' CSF NMDAR antibodies which, as previously reported, ${ }^{18,20,22}$ bind and internalize NMDARs, without inflammatory changes, but causing an impairment of memory and hippocampal plasticity for as long as the antibodies are present in the brain. The model has been useful in demonstrating the pathogenicity of patients' antibodies and offers the possibility of testing compounds of potential therapeutic utility, such as SGE-301.

Although the exact mechanism of action of SGE-301 has not been fully characterized, we and others previously reported that it increases channel's open probability and slows the decay phase of the spontaneous excitatory postsynaptic currents (EPSCs), potentiating NMDAR-mediated EPSCs. ${ }^{19,20,29}$ In a study in which cultured rat hippocampal neurons were exposed for 48 hours to patients' CSF or controls' CSF and during the last 24 hours, each condition was treated with SGE-301 or vehicle (no drug); those that were treated with SGE-301 showed increased NMDAR function compared with the untreated. ${ }^{29}$ In a previous report, we showed that SGE-301 antagonized the antibody-mediated reduction of NMDARs in cultured neurons and prevented the development of memory deficits in a model of cerebroventricular transfer of patients' CSF similar to that used here. ${ }^{20}$ Of interest, SGE-301 did not block the antibody binding to the brain but significantly decreased (without fully 


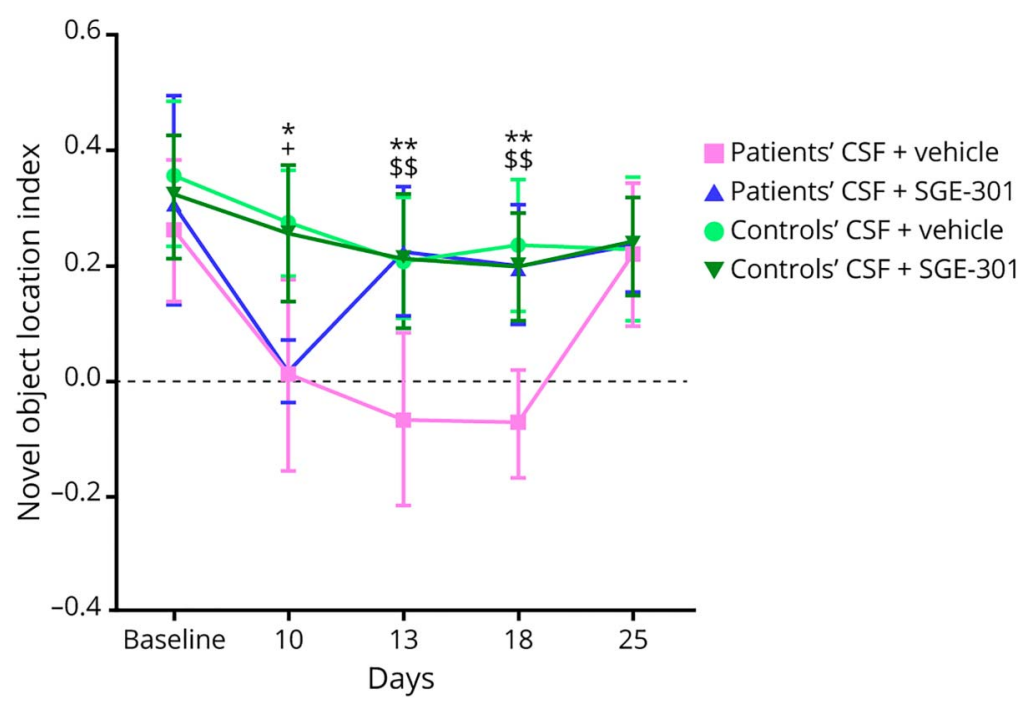

Mice infused with patients' CSF and treated with vehicle (pink line) showed a significant reduction of the Novel Object Location (NOL) index. This memory deficit was reversed in the group of mice infused with the same patients' CSF but treated from day 11 with SGE-301 (blue line). Note that by day 13 , the NOL index of these treated animals has recovered to levels similar to those of controls. No significant memory changes were noted in the groups of mice infused with controls' CSF and treated with vehicle (light green line) or SGE-301 (dark green line). Number of animals: controls' CSF + vehicle, $n=11$; patients' CSF + vehicle, $n=10$; controls' CSF + SGE-301, $\mathrm{n}=12 ;$ patients' CSF + SGE-301, $\mathrm{n}=11$. $\mathrm{A}$ higher NOL index represents better visuospatial memory. Data are presented as mean $\pm 95 \% \mathrm{Cl}$. Significance of assessment was performed by repeated-measures 2-way analysis of variance (ANOVA; $p<0.0001$ ) with Bonferron post hoc correction. Day 10 (pretreatment with SGE or vehicle): patients' CSF vs controls' CSF that will both start treatment with vehicle, * $p=0.0186$; patients' CSF vs controls' CSF that will both start treatment with SGE-301, $+p=0.0314$ Day 13: patients' CSF + vehicle vs controls' CSF + vehicle, ${ }^{* *} p$ $=0.0081$; patients' CSF + vehicle vs patients' CSF + SGE-301,

$\$ \$ p=0.0041$. Day 18: patients' CSF + vehicle vs controls' CSF + vehicle, ${ }^{* \star} p=0.0016$; patients' CSF + vehicle vs patients' CSF + SGE-301, $\$ p=0.0090$.

preventing) antibody-mediated NMDAR internalization. In addition, treatment with SGE-301 prevented the development of LTP impairment caused by patients' CSF antibodies. ${ }^{20}$ These and the current findings suggest that SGE-301 also increases the recruitment of NMDAR to the synapse to restore the levels and function of synaptic NMDARs. The exact mechanism that facilitates this recruitment is currently unknown and should be the focus of future investigations.

These studies, however, did not allow the assessment of whether SGE-301 is able to reverse the memory and synaptic alterations caused by patients' CSF because SGE-301 (used subcutaneously and at the same dose as here) was administered simultaneously with the ventricular infusion of patients' antibodies, and none of the animals developed clinical or synaptic alterations. ${ }^{20}$ Thus, we have adapted the model so that the administration of SGE-301 starts after synaptic and memory alterations have already developed. Of interest, between days 10 and 18, which in this model is the period of progressive development of severe memory and synaptic alterations, SGE-301 was able to reverse all antibody-mediated pathogenic effects (memory deficit, reduction of synaptic clusters of NMDARs, and LTP impairment) despite that during 4 days (days 10-14), animals continued receiving the infusion of patients' CSF.

We believe that the animal model used here is the best currently available model to assess the pathogenic effect of patients' CSF antibodies and the utility of drugs aimed to reverse this effect. Yet, the study has limitations inherent to this model. For example, we mainly focused on visuospatial memory as a surrogate marker of behavior because in this model, the memory deficit is the most severely affected paradigm and consistently shows a highly predictable alteration detectable from days 10 to 18 of patients' CSF infusion. This provides a good time interval of 9 days and an intermediate point of assessment (day 13) to determine the treatment efficacy of SGE-301 and to estimate the speed of recovery (e.g., by day 13, the memory deficit was already reversed and remained unaffected until the end of the experiment). The fact that the structural and functional synaptic alterations that underlie the symptoms of this model were also reversed supports the potential utility of PAMs of NMDARs as adjuvant treatment in the second stage of anti-NMDAR encephalitis. It is unclear whether SGE-301 may be effective in improving symptoms in the acute phase or first stage of the disease. In clinical practice, however, assessment of any adjuvant treatment in the acute phase will be challenging because of the presence of concurrent symptoms (seizures, dyskinesias, autonomic instability, or decreased level of consciousness), complications, and use of multiple different treatments. ${ }^{1,3,30}$

Overall, the current findings along with those of previous studies ${ }^{19,20,29}$ support the potential clinical utility of PAMs of NMDAR in patients with anti-NMDAR encephalitis and deserve future testing in the context of a clinical trial. There are ongoing studies with an oxysterol biology-based PAM closely related to SGE-301 (SAGE-718) optimized for clinical applications (e.g., oral bioavailability) that showed a good tolerability profile in healthy volunteers in a double-blind, placebo-controlled phase 1 single ascending disease study ${ }^{31}$ and is currently being used in a trial of Huntington disease (which at early stages, associates with hypofunction of NMDARs). Another task for the future is to assess the efficacy of oxysterol-based PAMs in an experimental setting that reproduces the acute inflammatory phase of antiNMDAR encephalitis, such as in a model of active immunization with NMDARs.

\section{Acknowledgment}

The authors thank Michael C. Quirk and Albert J. Robichaud from Sage Therapeutics, Cambridge, MA, USA, for their 
critical review of the manuscript, and Mercedes Alba and Eva Caballero (IDIBAPS, Hospital Clínic, University of Barcelona) for their technical support.

\section{Study Funding}

Plan Nacional de I+D+I and cofinanced by the ISCIIISubdirección General de Evaluación y Fomento de la Investigación Sanitaria and the Fondo Europeo de Desarrollo Regional (ISCIII-FEDER; FIS 20/00197, FIS 20/00280, FIS 018/00067, and FIS 17/00296); Project Integrative of Excellence (PIE16/00014); CIBERER (\#CB15/00010); "la Caixa” Banking Foundation (ID 100010434, under the agreement LCF/PR/ HR17/52150001); ERA-NET NEURON/Instituto Carlos III (AC18-00009); The Safra Foundation, and Fundació CELLEX; RETICs Oftared RD16/0008/0014; FI-AGAUR grant program by the Generalitat de Catalunya (2020FI_B2 00208); Maria de Maeztu MDM-2017-0729; and Basque Government Doctoral Fellowship Programme (PRE_2020_2_0219).

\section{Disclosure}

J.D. receives royalties from Athena Diagnostics for the use of $\mathrm{Ma} 2$ as an autoantibody test and from Euroimmun for the use of NMDA as an antibody test. He received a licensing fee from Euroimmun for the use of GABAB receptor, GABAA receptor, DPPX, and IgLON5 as autoantibody tests; he has received a research grant from Sage Therapeutics. M.L. works at Sage Therapeutics. M.R., J.P., F.M., A.M., E.A., L.S., J.L., A.G-S., E.M., and X.G. report no disclosures. Go to Neurology.org/NN for full disclosures.

\section{Publication History}

Received by Neurology: Neuroimmunology \& Neuroinflammation September 3, 2021. Accepted in final form October 21, 2021.

\section{Appendix Authors}

\begin{tabular}{lll}
\hline Name & Location & Contribution \\
\hline $\begin{array}{l}\text { Marija } \\
\text { Radosevic, }\end{array}$ & Institut d'Investigacions & Biomèdiques August Pi i \\
PhD & $\begin{array}{l}\text { Sunyer (IDIBAPS), Hospital } \\
\text { Clínic, Universitat de }\end{array}$ & $\begin{array}{l}\text { mancrision of the } \\
\text { including medical writing for } \\
\text { content; major role in the } \\
\text { Barcelona, Barcelona, Spain } \\
\text { acquisition of data; study } \\
\text { concept or design; and } \\
\text { analysis or interpretation of } \\
\text { data }\end{array}$ \\
\end{tabular}

\begin{tabular}{lll}
\hline $\begin{array}{l}\text { Jesús } \\
\text { Planagumà, } \\
\text { PhD }\end{array}$ & $\begin{array}{l}\text { Institut d'Investigacions } \\
\text { Biomèdiques August Pi i } \\
\text { Sunyer (IDIBAPS), Hospital } \\
\text { Clínic, Universitat de } \\
\text { Barcelona, Barcelona, Spain }\end{array}$ & $\begin{array}{l}\text { Drafting/revision of the } \\
\text { manuscript for content, } \\
\text { including medical writing for } \\
\text { content; major role in the } \\
\text { acquisition of data; study } \\
\text { concept or design; and } \\
\text { analysis or interpretation of } \\
\text { data }\end{array}$ \\
\hline $\begin{array}{l}\text { Francesco } \\
\text { Mannara, }\end{array}$ & $\begin{array}{l}\text { Institut d'Investigacions } \\
\text { Biomèdiques August Pi i } \\
\text { Sunyer (IDIBAPS), Hospital } \\
\text { Clínic, Universitat de } \\
\text { Barcelona, Barcelona, Spain }\end{array}$ & $\begin{array}{l}\text { Drafting/revision of the } \\
\text { manuscript for content, } \\
\text { including medical writing for } \\
\text { content; major role in the } \\
\text { acquisition of data; study } \\
\text { concept or design; and } \\
\text { analysis or interpretation of } \\
\text { data }\end{array}$ \\
& &
\end{tabular}

Appendix (continued)

\begin{tabular}{|c|c|c|}
\hline Name & Location & Contribution \\
\hline $\begin{array}{l}\text { Araceli } \\
\text { Mellado, BS }\end{array}$ & $\begin{array}{l}\text { Institut d'Investigacions } \\
\text { Biomèdiques August Pi i } \\
\text { Sunyer (IDIBAPS), Hospital } \\
\text { Clínic, Universitat de } \\
\text { Barcelona, Barcelona, Spain }\end{array}$ & $\begin{array}{l}\text { Major role in the acquisition } \\
\text { of data }\end{array}$ \\
\hline $\begin{array}{l}\text { Esther } \\
\text { Aguilar, BS }\end{array}$ & $\begin{array}{l}\text { Institut d'Investigacions } \\
\text { Biomèdiques August Pi i } \\
\text { Sunyer (IDIBAPS), Hospital } \\
\text { Clínic, Universitat de } \\
\text { Barcelona, Barcelona, } \\
\text { Spain }\end{array}$ & $\begin{array}{l}\text { Major role in the acquisition } \\
\text { of data }\end{array}$ \\
\hline $\begin{array}{l}\text { Lidia } \\
\text { Sabater, } \\
\text { PhD }\end{array}$ & $\begin{array}{l}\text { Institut d'Investigacions } \\
\text { Biomèdiques August Pi i } \\
\text { Sunyer (IDIBAPS), Hospital } \\
\text { Clínic, Universitat de } \\
\text { Barcelona, Barcelona, Spain }\end{array}$ & $\begin{array}{l}\text { Analysis or interpretation of } \\
\text { data; additional } \\
\text { contributions: acquisition of } \\
\text { data }\end{array}$ \\
\hline $\begin{array}{l}\text { Jon Landa, } \\
\text { MSc }\end{array}$ & $\begin{array}{l}\text { Institut d'Investigacions } \\
\text { Biomèdiques August Pi i } \\
\text { Sunyer (IDIBAPS), Hospital } \\
\text { Clínic, Universitat de } \\
\text { Barcelona, Barcelona, Spain }\end{array}$ & $\begin{array}{l}\text { Additional contributions: } \\
\text { acquisition of data }\end{array}$ \\
\hline $\begin{array}{l}\text { Anna } \\
\text { García- } \\
\text { Serra, PhD }\end{array}$ & $\begin{array}{l}\text { Institut d'Investigacions } \\
\text { Biomèdiques August Pi i } \\
\text { Sunyer (IDIBAPS), Hospital } \\
\text { Clínic, Universitat de } \\
\text { Barcelona, Barcelona, Spain }\end{array}$ & $\begin{array}{l}\text { Additional contributions: } \\
\text { acquisition of data }\end{array}$ \\
\hline $\begin{array}{l}\text { Estibaliz } \\
\text { Maudes, } \\
\text { MSc }\end{array}$ & $\begin{array}{l}\text { Institut d'Investigacions } \\
\text { Biomèdiques August Pi i } \\
\text { Sunyer (IDIBAPS), Hospital } \\
\text { Clínic, Universitat de } \\
\text { Barcelona, Barcelona, Spain }\end{array}$ & $\begin{array}{l}\text { Additional contributions: } \\
\text { acquisition of data }\end{array}$ \\
\hline $\begin{array}{l}\text { Xavier } \\
\text { Gasull, PhD }\end{array}$ & $\begin{array}{l}\text { Institut d'Investigacions } \\
\text { Biomèdiques August Pi i } \\
\text { Sunyer (IDIBAPS), Hospital } \\
\text { Clínic, Universitat de } \\
\text { Barcelona, Barcelona, Spain; } \\
\text { Laboratori de } \\
\text { Neurofisiologia, } \\
\text { Departament de } \\
\text { Biomedicina, Facultat de } \\
\text { Medicina i Ciències de la } \\
\text { Salut, Institut de } \\
\text { Neurociències, Universitat } \\
\text { de Barcelona, Barcelona, } \\
\text { Spain }\end{array}$ & $\begin{array}{l}\text { Analysis or interpretation of } \\
\text { data }\end{array}$ \\
\hline $\begin{array}{l}\text { Mike Lewis, } \\
\text { PhD }\end{array}$ & $\begin{array}{l}\text { Sage Therapeutics, } \\
\text { Department of Research and } \\
\text { Nonclinical Development, } \\
\text { Cambridge, MA }\end{array}$ & $\begin{array}{l}\text { Drafting/revision of the } \\
\text { manuscript for content, } \\
\text { including medical writing for } \\
\text { content; study concept or } \\
\text { design; and analysis or } \\
\text { interpretation of data }\end{array}$ \\
\hline $\begin{array}{l}\text { Josep } \\
\text { Dalmau, } \\
\text { MD, PhD }\end{array}$ & $\begin{array}{l}\text { Institut d'Investigacions } \\
\text { Biomèdiques August Pi i } \\
\text { Sunyer (IDIBAPS), Hospital } \\
\text { Clínic, Universitat de } \\
\text { Barcelona, Barcelona, Spain; } \\
\text { Department of Neurology, } \\
\text { University of Pennsylvania, } \\
\text { Philadelphia, PA; Institució } \\
\text { Catalana de Recerca i Estudis } \\
\text { Avançats (ICREA), Barcelona, } \\
\text { Spain }\end{array}$ & $\begin{array}{l}\text { Drafting/revision of the } \\
\text { manuscript for content, } \\
\text { including medical writing for } \\
\text { content; study concept or } \\
\text { design; and analysis or } \\
\text { interpretation of data }\end{array}$ \\
\hline
\end{tabular}

\section{References}

1. Dalmau J, Gleichman AJ, Hughes EG, et al. Anti-NMDA-receptor encephalitis: case series and analysis of the effects of antibodies. Lancet Neurol. 2008;7(12): 1091-1098. 
2. Florance NR, Davis RL, Lam C, et al. Anti-N-methyl-D-aspartate receptor (NMDAR) encephalitis in children and adolescents. Ann Neurol. 2009;66(1):11-18.

3. Titulaer MJ, McCracken L, Gabilondo I, et al. Treatment and prognostic factors for long-term outcome in patients with anti-NMDA receptor encephalitis: an observational cohort study. Lancet Neurol. 2013;12(2):157-165.

4. Ariño H, Muñoz-Lopetegi A, Martinez-Hernandez E, et al. Sleep disorders in antiNMDAR encephalitis. Neurology. 2020;95(6):e671-e684.

5. Wang W, Li JM, Hu FY, et al. Anti-NMDA receptor encephalitis: clinical characteristics, predictors of outcome and the knowledge gap in southwest China. Eur J Neurol. 2016;23(3):621-629.

6. Zhang Y, Liu G, Jiang M, Chen W, He Y, Su Y. Clinical characteristics and prognosis of severe anti-N-methyl-D-aspartate receptor encephalitis patients. Neurocrit Care. 2018; 29(2):264-272.

7. $\mathrm{Xu} \mathrm{X,} \mathrm{Lu} \mathrm{Q,} \mathrm{Huang} \mathrm{Y,} \mathrm{et} \mathrm{al.} \mathrm{Anti-NMDAR} \mathrm{encephalitis:} \mathrm{a} \mathrm{single-center,} \mathrm{longitudinal}$ study in China. Neurol Neuroimmunol Neuroinflamm. 2020;7(1):e633.

8. Dalmau J, Lancaster E, Martinez-Hernandez E, Rosenfeld MR, Balice-Gordon R. Clinical experience and laboratory investigations in patients with anti-NMDAR encephalitis. Lancet Neurol. 2011;10(1):63-74.

9. Finke C, Kopp UA, Prüss H, Dalmau J, Wandinger KP, Ploner CJ. Cognitive deficits following anti-NMDA receptor encephalitis. J Neurol Neurosurg Psychiatry. 2012; 83(2):195-198.

10. Shim Y, Kim SY, Kim H, et al. Clinical outcomes of pediatric Anti-NMDA receptor encephalitis. Eur J Paediatr Neurol. 2020;29:87-91.

11. Blum RA, Tomlinson AR, Jetté N, Kwon CS, Easton A, Yeshokumar AK. Assessment of long-term psychosocial outcomes in anti-NMDA receptor encephalitis. Epilepsy Behav. 2020;108:107088.

12. Tomlinson AR, Blum RA, Jetté N, Kwon CS, Easton A, Yeshokumar AK. Assessment of care transitions and caregiver burden in anti-NMDA receptor encephalitis. Epilepsy Behav. 2020;108:107066.

13. de Bruijn M, Aarsen FK, van Oosterhout MP, et al. Long-term neuropsychological outcome following pediatric anti-NMDAR encephalitis. Neurology. 2018;90(22): e1997-e2005.

14. Hughes EG, Peng X, Gleichman AJ, et al. Cellular and synaptic mechanisms of antiNMDA receptor encephalitis. J Neurosci. 2010;30(17):5866-5875.

15. Zrzavy T, Endmayr V, Bauer J, et al. Neuropathological variability within a spectrum of NMDAR-encephalitis. Ann Neurol. 2021;90:725-737.

16. Wirtz PW, Titulaer MJ, Gerven JM, Verschuuren JJ. 3,4-diaminopyridine for the treatment of Lambert-Eaton myasthenic syndrome. Expert Rev Clin Immunol. 2010; 6(6):867-874.

17. Newsom-Davis J. Therapy in myasthenia gravis and Lambert-Eaton myasthenic syndrome. Semin Neurol. 2003;23(2):191-198.
18. Planagumà J, Leypoldt $\mathrm{F}$, Mannara $\mathrm{F}$, et al. Human $\mathrm{N}$-methyl $\mathrm{D}$-aspartate receptor antibodies alter memory and behaviour in mice. Brain. 2015;138(pt 1) 94-109.

19. Paul SM, Doherty JJ, Robichaud AJ, et al. The major brain cholesterol metabolite 24(S)-hydroxycholesterol is a potent allosteric modulator of N-methyl-D-aspartate receptors. J Neurosci. 2013;33(44):17290-17300.

20. Mannara F, Radosevic M, Planagumà J, et al. Allosteric modulation of NMDA receptors prevents the antibody effects of patients with anti-NMDAR encephalitis. Brain. 2020;143(9):2709-2720.

21. Shu HJ, Zeng CM, Wang C, Covey DF, Zorumski CF, Mennerick S. Cyclodextrins sequester neuroactive steroids and differentiate mechanisms that rate limit steroid actions. Br J Pharmacol. 2007;150(2):164-175.

22. Planagumà J, Haselmann H, Mannara F, et al. Ephrin-B2 prevents N-methyl-D aspartate receptor antibody effects on memory and neuroplasticity. Ann Neurol.2016; 80(3):388-400.

23. Moscato EH, Peng X, Jain A, Parsons TD, Dalmau J, Balice-Gordon RJ. Acute mechanisms underlying antibody effects in anti-N-methyl-D-aspartate receptor encephalitis. Ann Neurol. 2014;76(1):108-119.

24. Dalmau J, Armangué T, Planagumà J, et al. An update on anti-NMDA receptor encephalitis for neurologists and psychiatrists: mechanisms and models. Lance Neurol. 2019;18(11):1045-1057.

25. Viaccoz A, Desestret V, Ducray F, et al. Clinical specificities of adult male patients with NMDA receptor antibodies encephalitis. Neurology. 2014;82(7):556-563.

26. Irani SR, Bera $\mathrm{K}$, Waters $\mathrm{P}$, et al. $\mathrm{N}$-methyl-D-aspartate antibody encephalitis: temporal progression of clinical and paraclinical observations in a predominantly nonparaneoplastic disorder of both sexes. Brain. 2010;133(pt 6):1655-1667.

27. Gresa-Arribas N, Titulaer MJ, Torrents A, et al., Antibody titres at diagnosis and during follow-up of anti-NMDA receptor encephalitis: a retrospective study. Lance Neurol. 2014;13:167-177.

28. Nosadini M, Mohammad SS, Toldo I, Sartori S, Dale RC. Mycophenolate mofetil, azathioprine and methotrexate usage in paediatric anti-NMDAR encephalitis: a systematic literature review. Eur J Paediatr Neurol. 2019;23(1):7-18.

29. Warikoo N, Brunwasser SJ, Benz A, et al. Positive allosteric modulation as a potential therapeutic strategy in anti-NMDA receptor encephalitis. J Neurosci. 2018;38(13) 3218-3229.

30. de Montmollin E, Demeret S, Brule N, et al. Anti-N-methyl-d-aspartate receptor encephalitis in adult patients requiring intensive care. Am J Respir Crit Care Med. 2017, 195(4):491-499.

31. Koenig A, Murck H, Paskavitz J, et al. Double-blind, placebo-controlled phase 1 single ascending dose study of SAHE-718. International College of Neuropsychopharmacology (CINP) 2019 Congress. Athens, Greece, 2019. 


\title{
Neurology \\ Neuroimmunology \& Neuroinflammation
}

\author{
Allosteric Modulation of NMDARs Reverses Patients' Autoantibody Effects in Mice \\ Marija Radosevic, Jesús Planagumà, Francesco Mannara, et al. \\ Neurol Neuroimmunol Neuroinflamm 2022;9; \\ DOI 10.1212/NXI.0000000000001122
}

This information is current as of December 13, 2021

\section{Updated Information \& Services}

References

Subspecialty Collections

Permissions \& Licensing

Reprints including high resolution figures, can be found at: http://nn.neurology.org/content/9/1/e1122.full.html

This article cites 30 articles, 4 of which you can access for free at: http://nn.neurology.org/content/9/1/e1122.full.html\#\#ref-list-1

This article, along with others on similar topics, appears in the following collection(s):

Autoimmune diseases

http://nn.neurology.org//cgi/collection/autoimmune_diseases

Information about reproducing this article in parts (figures,tables) or in its entirety can be found online at:

http://nn.neurology.org/misc/about.xhtml\#permissions

Information about ordering reprints can be found online: http://nn.neurology.org/misc/addir.xhtml\#reprintsus

Neurol Neuroimmunol Neuroinflamm is an official journal of the American Academy of Neurology.

Published since April 2014, it is an open-access, online-only, continuous publication journal. Copyright

Copyright (C) 2021 The Author(s). Published by Wolters Kluwer Health, Inc. on behalf of the American Academy of Neurology.. All rights reserved. Online ISSN: 2332-7812.

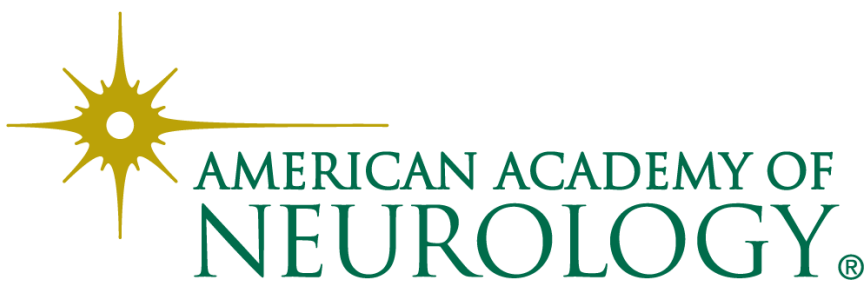

